\title{
VARIAÇÃO TEMPORAL DAS CHUVAS EM JANUÁRIA, CARINHANHA E MONTES CLAROS, NORTE DO ESTADO DE MINAS GERAIS
}

\author{
Felipe Pereira de Moura ${ }^{(a)}$; Carlos Henrique Jardim ${ }^{(b)}$ \\ (a) Graduando, Depto. Geografia/IGC, UFMG, felipegeografia@ hotmail.com \\ (b) Prof. Adjunto, Depto. Geografia/IGC, UFMG, dxhenrique @ gmail.com
}

\section{Eixo: Climatologia em Diferentes Níveis Escalares: Mudanças e Variabilidades}

\section{Resumo}

O presente artigo analisa aspectos da variação das chuvas no norte de Minas Gerais, a partir de dados das séries temporais das estações meteorológicas nos municípios de Montes Claros, Januária e Carinhanha, considerando os totais anuais de chuva, valores de tendência e correlação e desvios percentuais. Os resultados mostraram relação dos dados mensurados com fatores em diferentes escalas, ligados à ação das massas de ar em teleconexão com fenômenos climáticos de larga escala, e com o relevo, responsável por variações locais.

Palavras chave: chuvas, massas de ar, relevo, variabilidade climática.

\section{Introdução}

A variação temporal e espacial das chuvas, um dos atributos mais importantes do clima principalmente em regiões de clima tropical, pode ser compreendida como um sistema de relações entre os atributos atmosféricos (ventos, temperatura, umidade etc.) com os fatores geográficos de superfície (relevo, uso da terra, latitude, distância em relação aos oceanos etc.). Mesmo que a dinâmica atmosférica relativa à circulação do ar em meso e macroescala responda por grande parte da gênese desse atributo, o seu impacto só poderá ser compreendido considerando as características e dinâmica dos fatores sobre a superfície (correntes oceânicas, relevo, biomas e domínios fitogeográficos etc.), por outras palavras, seria interessante maior entrosamento entre o conhecimento geográfico e aquele da meteorologia.

Nos trópicos a chuva é o principal elemento de caracterização do clima, cuja compreensão é fundamental para o ser humano se organizar no ambiente onde vive. Exemplo disso é discutido por Monteiro (1971) quando enfatiza a necessidade em se compreender os desvios nas variações dos atributos do clima em relação às médias. E o fato da gênese das chuvas no território brasileiro estar essencialmente ligada à dinâmica das massas de ar como coloca Tarifa (1993), torna ainda mais relevante essa consideração.

Fatores como o relevo, diferentemente da ação das massas de ar, atuam modulando localmente as variações dos atributos climáticos, reforçando ou atenuando o impacto sobre a superfície. Conti (2001) 


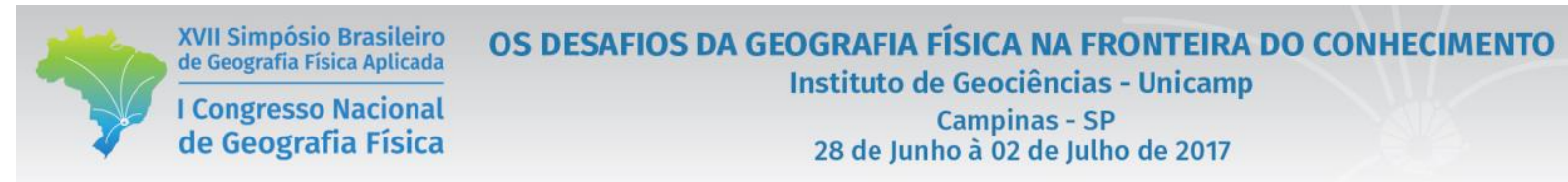

traz exemplo concreto dessa integração ao descrever os impactos das chuvas em área da Serra da Mantiqueira, associados a escorregamentos de solo, entre os estados de São Paulo, Minas Gerais e Rio de Janeiro.

O presente resumo traz resultados parciais de projeto em andamento (Projeto APQ-03773-14 Sustentabilidade da bacia do Rio Pandeiros-MG financiado pela Fundação de Amparo à Pesquisa do Estado de Minas Gerais - FAPEMIG), cujo objetivo, no presente caso, envolve a compreensão e caracterização da dinâmica das chuvas na região de Januária, norte do estado de Minas Gerais, a partir de sua relação com a dinâmica atmosférica.

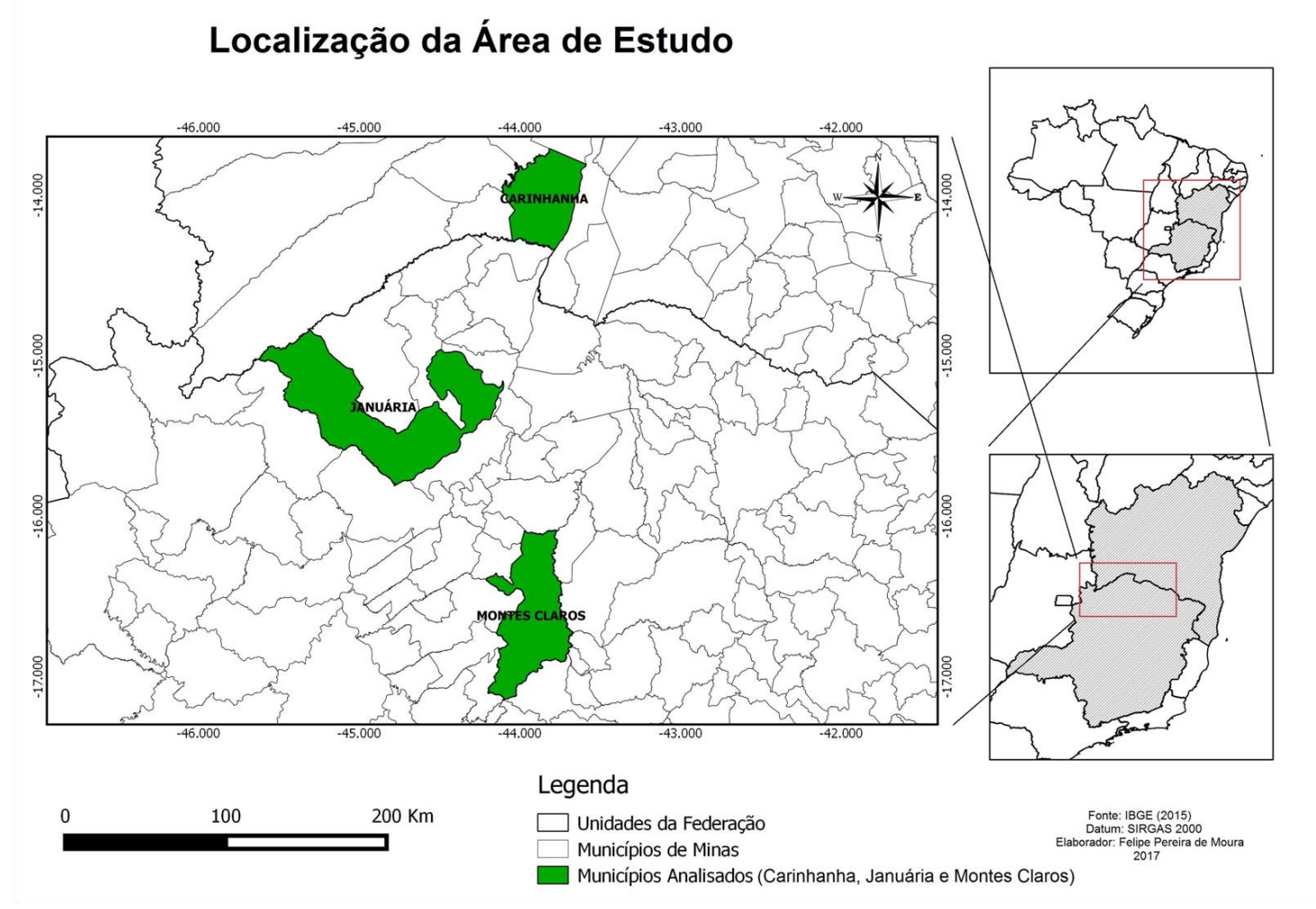

Figura 1 - Localizaçao da área de estudo. Elaboração: Felipe P. Moura.

A área de estudo (figura 1) compreende o eixo entre os municípios de Montes Claros e Januária no norte do estado de Minas Gerais e Carinhanha no sudoeste da Bahia. Apesar da análise focar na variabilidade das chuvas da localidade de Januária, conforme objetivo geral do projeto mencionado, houve necessidade de incluir séries temporais de chuva de outras localidades a fim de compreender essas variações no âmbito regional. 


\section{Materiais e Métodos}

As séries anuais de dados (1961-2015) foram obtidas das estações meteorológicas do Instituto Nacional de Meteorologia - INMET (www.inmet.gov.br) através do Banco de Dados Meteorológicos para Ensino e Pesquisa (BDMEP), localizadas nos municípios de Januária e Montes Claros em Minas Gerais e Carinhanha no estado da Bahia. Foram consultados, também, dados das Normais Climatológicas 19611990 (DNMET, 1992).

Inicialmente foi realizada a verificação da consistência dos dados, eliminando-se anos com mais de dois meses sem dados. Para a correção de anos com até dois meses faltantes utilizou-se a média simples aritmética daquele mês. Os dados foram tabulados e trabalhados através de procedimentos estatísticos básicos, utilizando-se do software Microsoft Excel (versão 2010). Com os dados obtidos elaboraram-se tabelas e gráficos referentes ao acumulado de precipitação e os desvios em relação às médias.

A comparação dos dados oriundos das três estações representativas dentro do espaço regional do norte de Minas Gerais, com informações relativas ao ambiente físico (relevo, latitude etc.) e amtosférico ligados à ação das massas de ar em teleconexão (ou não) com mecanismos como o El Niño, La Niña e Oscilação Decadal do Pacífico (ODP), permitiu avaliar aspectos da variablidade das chuvas nessa região.

\section{Resultados}

Inicialmente pode-se destacar o componente zonal, ligado à variação latitudinal, entre as estações na área de estudo. De acordo com a Tabela I, isso é visível na elevação das temperaturas e evaporação e redução dos totais de chuvas em direção à Carinhanha. Entretanto, essa variação não é uniforme o que evidencia a ação de componentes dinâmicos associados ação das massas de ar e locais ligados ao relevo.

Tabela I - Valores médios anuais para os atributos do clima na área de estudo.

\begin{tabular}{|c|c|c|c|c|c|c|c|}
\hline & \multicolumn{3}{|c|}{ Temperatura $\left({ }^{\circ} \mathrm{C}\right)$} & \multirow{2}{*}{$\begin{array}{c}\text { Insolação } \\
\text { (horas) }\end{array}$} & \multirow{2}{*}{$\begin{array}{l}\text { Evap. } \\
\text { (mm) }\end{array}$} & \multirow{2}{*}{$\begin{array}{c}\text { Umid. Relativa } \\
(\%)\end{array}$} & \multirow{2}{*}{$\begin{array}{c}\text { Precipit. } \\
\text { (mm) }\end{array}$} \\
\hline & média & máxima & mínima & & & & \\
\hline Montes Claros & 22,4 & 29,3 & 16,7 & 2642,6 & 1359,5 & 66,6 & 1082,3 \\
\hline Januária & 24,2 & 30,9 & 18,4 & 2786,3 & 1539,1 & 66,3 & 826,5 \\
\hline Carinhanha & 25 & 31,2 & 19,1 & 2821 & 2304,1 & 57,5 & 813,7 \\
\hline
\end{tabular}

Fonte: DNMET (1992). 


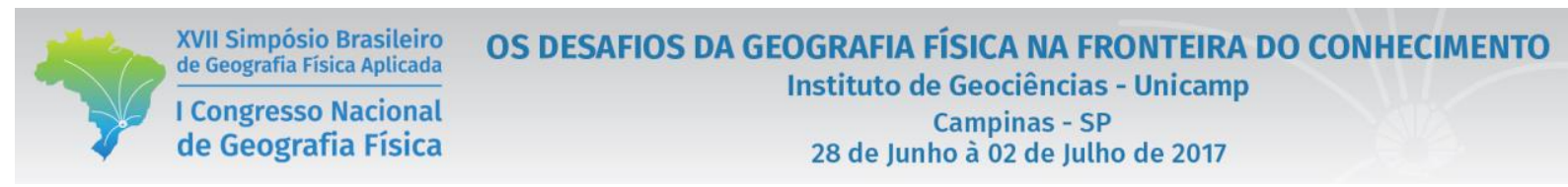

A presença de lacunas na série de Carinhanha torna difícil a comparação. Entretanto, como mostra os gráficos a seguir (figuras 2), há relação entre as fases da ODP com os desvios dos totais de chuva (fase positiva com predomínio de desvios positivos e o contrário para fases negativas). Entretando, a ação de El Niños fortes tendem a inibir essa tendência particularmente na região nordeste (ou em áreas próximas, caso da área de estudo aqui tratada) onde o seu sinal é forte.
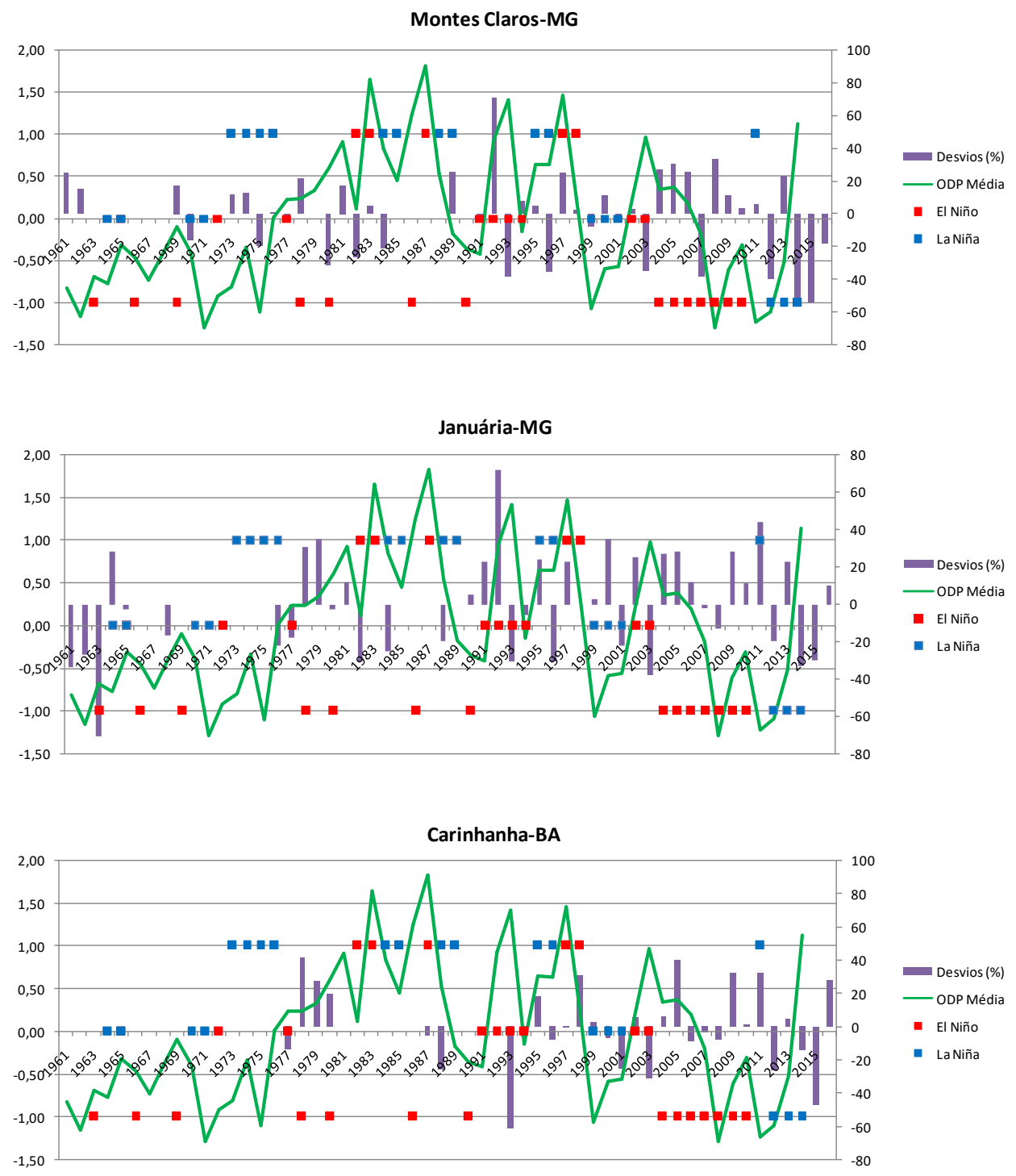

Figura 2 - Desvios (\%) dos totais de chuva (eixo esquerdo) para o período de 1961-2015 e relação com ODP, El Niño e La Niña (eixo da direita). El Niño/La Niña: forte (+1); moderado (0); fraco (-1). Elaboração: Carlos H. Jardim/Felipe Pereira de Moura. 


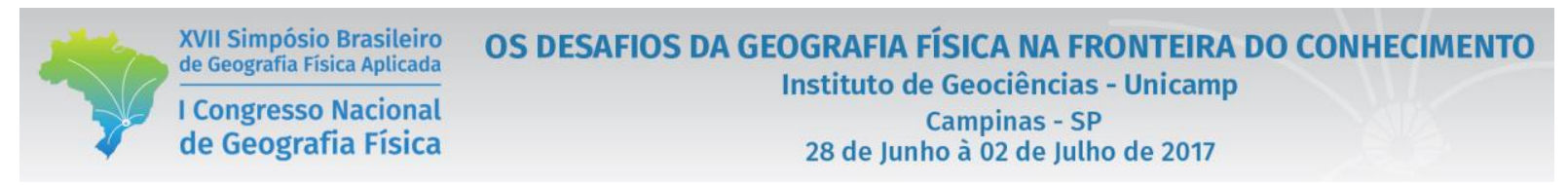

Embora permaneça no interior da área de influência de regime tropical de chuvas do Brasil Central, de acordo com Nimer (1989), com chuvas concentradas no trimestre de verão, os desvios (média anual em relação à normal) são significativamente elevados 20 a 25\%, superiores ao centro-sul de Minas Gerais (10 a 15\%), e aumentando na direção dos núcleos de semiaridez da região nordeste.

As razões para isso encontram-se no padrão de circulação atmosférica estabelecido com reforço do ar subsidente do ASAS (Anciclone Subtropical do Atlântico Sul) sobre as regiões norte e nordeste, ligado à condições de estabilidade. O seu alcance em termos de dimensão pode limitar ou ampliar o limite definido pela zona de bloqueio atmosférico em direção a latitudes mais altas sobre o sudeste brasileiro, dificultando a formação de linhas de instabilidade e o avanço das frentes frias e em direção a latitudes baixas. Isso pode ser verificado comparativamente com Belo Horizonte no trabalho de Silva et al. (2017) quando as localidades de Montes Claros e Januária mostraram desvios negativos no El Niño de 1982/83, Belo Horizonte exibiu forte desvio positivo.

\section{Considerações Finais}

Os desvios em relação à média é fato comum na evolução temporal do clima, desencadeadas por processos cujo conhecimento aumenta exponencialmente com o decorrer do tempo, não havendo necessidade de evocar explicações pseudocientíficas associadas a mudanças climáticas. E o papel do ser humano, nesse sentido, não está na sua capacidade de alterar o clima (o que seria impossível), mas em melhorar a capacidade de suporte do ambiente frente aos impactos negativos produzidos pela natureza e/ou pela própria ação antrópica.

\section{Bibliografia}

CONTI, J. B. Resgatando a "fisiologia da paisagem". Revista do Departamento de Geografia, São Paulo (SP), n.14, p.59-68, 2001.

DNMET. Departamento Nacional de Meteorologia. Normais Climatológicas (1961- 1990). Brasília-DF, 1992.

MONTEIRO, C. A. F. Análise rítmica em climatologia. Problemas da atualidade climática em São Paulo e achegas para um programa de trabalho. Climatologia, São Paulo, n.01, p.1-21, 1971.

NIMER, E. Climatologia do Brasil. 2.ed. Rio de Janeiro: IBGE, 1989.

SILVA, M. R; MOURA, F. P; JARDIM, C. H. O diagrama de Caixa (Box Plot) Aplicado à Análise da Distribuição Temporal das Chuvas em Januária, Belo Horizonte e Sete Lagoas, Minas Gerais-Brasil. Revista Brasileira de Geografia Física (In press) v. 10, n.1, 2017.

TARIFA, J. R. Alterações climáticas resultantes da ocupação agrícola no Brasil. Revista do Departamento de Geografia, São Paulo, n. 8, p. 15-27, 1994. 